\title{
Good news about the ESNR-Springer Award
}

\author{
G. Wilms ${ }^{1}$ • R. von Kummer ${ }^{2,4}$ - M. Thurnher ${ }^{3}$
}

Received: 14 March 2016 / Accepted: 14 March 2016 / Published online: 1 April 2016

(C) Springer-Verlag Berlin Heidelberg 2016

Neuroradiology is the official journal of the European Society of Neuroradiology (ESNR), the Japanese Society of Neuroradiology, and of many other national societies and sections as listed in the printed issue of the journal and on the journal's webpage (http://www.springer.com/medicine/ radiology/journal/234/PSE?detailsPage=societies).

To honor this strong relation, the Executive Committee of ESNR, the Editor-in-Chief of the journal, and the Publisher decided 3 years ago to award a prize of 1000 EUR to the firstnamed author (who is an ESNR's Full, Associate, Junior, or Institutional Member) of the most cited article of the latest impact factor (for example: IF 2014: articles published in 2012 and 2013, citations in 2014). For the winners, ESNR offers a free registration for the ESNR meeting where the prize is awarded.

Since then, three prizes were awarded [1-3]. It was not surprising to see that all three prizes went to an interventional paper, since in this field a high turnover of innovative techniques tends to be reported, leading to many citations. Since the majority of papers though deal with diagnostic neuroradiology, we felt it was unfair that this was not rewarded.

R. von Kummer

Ruediger.vonKummer@uniklinikum-dresden.de

G. Wilms

guido.wilms@uzleuven.be

1 Department of Radiology, UZ-Gasthuisberg, Leuven, Belgium

2 Institute of Diagnostic and Interventional Neuroradiology, University Hospital Carl Gustav Carus, Fetscherstr. 74,

01307 Dresden, Germany

3 Department of Biomedical and Image-Guided Therapy, University Hospital Vienna, Vienna, Austria

4 Broekstraat 125, 3001 Heverlee, Belgium
Therefore, we are extremely grateful to the Publisher to accept our proposal to award a second prize in this category. So from this year on, there will be two ESNR-Springer Awards, one for diagnostic and one for interventional neuroradiology, both for the amount of 1000 EUR. The winners will be granted free access by ESNR to the annual congress of the ESNR in Belgrade from September 15 to 18 , where the awards will be announced and given during the Annual Awards Ceremony and where the winners will give a short presentation of their paper. We wish all authors success with their published papers and hope they are cited enough to win one of both prizes.

(1) Guido Wilms is Editor-in-Chief of Neuroradiology.

(2) Rudiger von Kummer is Chair of the ESNR Award Committee.

(3) Majda Thurnher is President of the ESNR.

\section{References}

1. Bernd T, Stephan M, Zolt K, Daniel H, Walter S (2011) Early fatal hemorrhage after endovascular cerebral aneurysm treatment with a flow diverter (SILK-Stent): do we need to rethink our concept? Neuroradiology 53(1):37-41, First online 2010 Mar 26 (Winner 2013)

2. Fischer S, Vajda Z, Aguilar Perez M, Schmid E, Hopf N, Bäzner H, Henkes H (2012) Pipeline embolization device (PED) for neurovascular reconstruction: initial experience in the treatment of 101 intracranial aneurysms and dissections. Neuroradiology 54(4): 369-382, First online: 01 September 2011 (Winner 2014)

3. Briganti F, Napoli M, Tortora F, Solari D, Bergui M, Boccardi E, Cagliari E, Castellan L, Causin F, Ciceri E, Cirillo L, De Blasi R, Delehaye L, Di Paola F, Fontana A, Gasparotti R, Guidetti G, Divenuto I, Iannucci G, Isalberti M, Leonardi M, Lupo F, Mangiafico S, Manto A, Menozzi R, Muto M, Nuzzi NP, Papa R, Petralia B, Piano M, Resta M, Padolecchia R, Saletti A, Sirabella G, Bolgè LP (2012) Italian multicenter experience with flow-diverter devices for intracranial unruptured aneurysm treatment with periprocedural complications - a retrospective data analysis. Neuroradiology 54(10):1145-115, First online: 09 May 2012 (Winner 2015) 